\title{
Bilateral Traumatic Maculopathy after Closed-Globe Injury in Context of National Lockdown: A Case Report
}

\author{
Amin Bennedjai ${ }^{a} \quad$ Raphaël Adam ${ }^{a} \quad J a d$ Akesbi ${ }^{a} \quad$ Thibaut Rodallec ${ }^{a}$ \\ Raoul Vidal $^{\mathrm{b}}$ Romain Gaillard ${ }^{\mathrm{a}}$ Jean-Philippe Nordmann ${ }^{\mathrm{a}}$ \\ aDepartment of Ophthalmology 2, Quinze-Vingts National Ophthalmology Hospital, IHU \\ FOReSIGHT, University Paris Descartes, Paris, France; ${ }^{b}$ Ophtalmologue, Paris, France
}

\author{
Keywords \\ Closed-globe injury · Traumatic maculopathy
}

\begin{abstract}
The aim of this study is to report a case of bilateral traumatic maculopathy in a 19-year-old male following blunt trauma during 2020 coronavirus disease-2019 national lockdown. Descriptive case report based on data from clinical records, patient observation, and analysis of diagnostic tests. A previously healthy, 19-year-old male presented for a visit in our department at 15-20 National Ophthalmology Institute with complaints of bilateral decreased visual acuity. A history of recent blunt trauma caused by resistance band was reported. Fundus examination recorded fibrosis and inferior preretinal hemorrhages on both eyes. Peripheral retinal examination was normal. Optical coherence tomography showed bilateral increased reflectivity, disruption of the inner/outer segment, and loss of the external limiting membrane. The 6-week follow-up did not show a major recovery. Early detection of posterior segment damage after blunt trauma remains primordial despite worldwide pandemic.
\end{abstract}

(C) 2021 The Author(s).

Published by S. Karger AG, Basel

\section{Introduction}

Following the outbreak of coronavirus disease-2019 (COVID-19) in December 2019, ocular abnormalities linked with the virus have been reported [1]. Most of them were conjunctivitis according to $\mathrm{Wu}$ et al. [1]. The worldwide epidemic [2] leaded to a strict home confinement policy in France lasting 2 months. Many domestic accidents were thus reported by emergency departments [3]. Eye injuries increased during this period worsened by the delay in diagnoses. Posterior segment damage after blunt trauma often coexists with anterior segment damage but can occur independently [4]. The macula is extremely vulnerable to 
trauma. 'Berlin's edema can be observed after ocular blunt trauma. Patients usually complain about a decrease in visual acuity, and a transient gray-white retinal coloration is seen within fundus examination [5]. Spectral-domain optical coherence tomography (OCT) usually reveals retinal atrophy, pigment disorders, and disruption of the outer segment (OS) junction associated with corresponding hyper-reflectivity of the overlying retina [6]. Fundus examination at acute phase can show retinal or intravitreal hemorrhages [7].

\section{Case Presentation}

A previously healthy, 19-year-old male presented for a visit in our department at 15-20 National Ophthalmology Institute with complaints of bilateral decreased visual acuity. He reported a blunt trauma on both eyes 8 days before due to resistance band (Fig. 1) used for strengths exercises at home. He went through ophthalmological examination in another department the day of the trauma. At the visit, best-corrected visual acuity (BCVA) in right eye (RE) was 20/400 and 20/1,000 in the left eye. Slit-lamp examination did not show any scleral wound, corneal wound, or traumatism of the lens. Air-puffed intraocular pressure (IOP) was $14 \mathrm{~mm} \mathrm{Hg}$ in the RE and 16 $\mathrm{mm} \mathrm{Hg}$ in the left eye (LE). Air-puffed IOP device was used due to the risk of unknown scleral perforation in this traumatic context. Devices were cleaned with sanitizing spray after each examination, and a time-period of $15 \mathrm{~min}$ was respected between each patient examination in accordance with Hygiene Department guidelines. Fundus examination showed bilateral preretinal hemorrhages not allowing further examination. B-ultrasonography revealed no evidence of retinal tears or retinal detachment. No treatment has been started. The patient could not be referred initially to a reference center due to national lockdown while COVID-19 was spreading. One week later, BCVA was below 20/200 on RE and 20/1,000 on LE. IOP was $12 \mathrm{~mm} \mathrm{Hg}$ on both eyes. Fundus examination after a 7-day delay recorded inferotemporal rupture of Bruch membrane on RE and inferior diffuse preretinal hemorrhages on both eyes. Fundus autofluorescence demonstrated increased autofluorescence in traumatic pigment epitheliopathy (Fig. 2). Peripheral retinal examination was normal. Spectral-domain OCT (Heidelberg Engineering Inc., Heidelberg, Germany) showed bilateral increased reflectivity, disruption of the inner/OS (IS/OS), and loss

Fig. 1. Example of resistance band strength exercise.

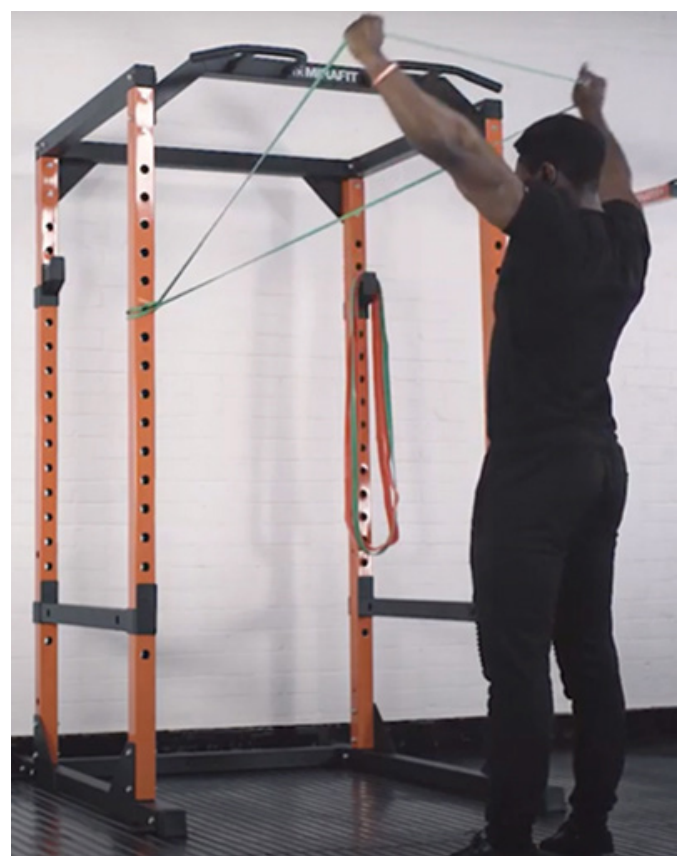




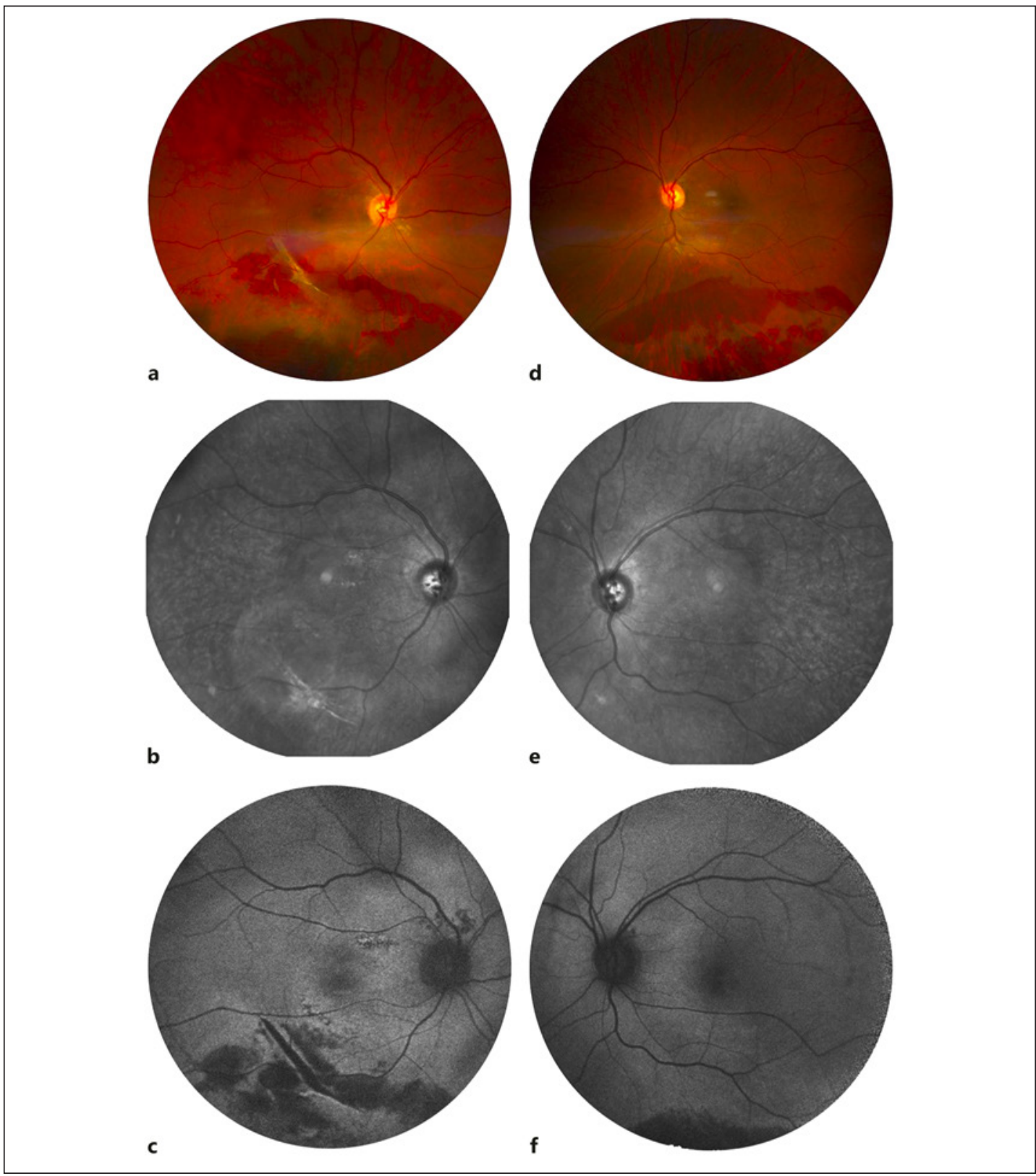

Fig. 2. Bilateral fundus presentation after a 7-day delay showing preretinal inferior hemorrhages on retinophotography (a, d) (Clarus, Zeiss Inc., Oberkochen, Germany), infrared cliche (b, e), and autofluorescence (c, f) (Heidelberg Engineering Inc., Heidelberg, Germany).

of the external limiting membrane in the macular area (Fig. 3). A full-thickness thin macular hole was present only on RE. Retinal thickness was decreased below $200 \mu \mathrm{m}$ at the sites of the lesions. We decided to introduce oral steroids therapy $40 \mathrm{mg}$ a day. The patient has been notified of the poor prognosis. The 6-week follow-up revealed a BCVA at 20/80 on RE and $20 / 63$ on LE. The fundus examination showed a slight decrease of preretinal hemorrhages on both eyes. Spectral-domain OCT (Heidelberg Engineering Inc., Heidelberg, Germany) showed a spontaneous closure of macular hole on RE, and however, outer retinal layers remained atrophic on both eyes (Fig. 3). No macular hole was present on left eye. The subject had given his written informed consent for publication of its case. 


\section{Case Reports in Ophthalmology}
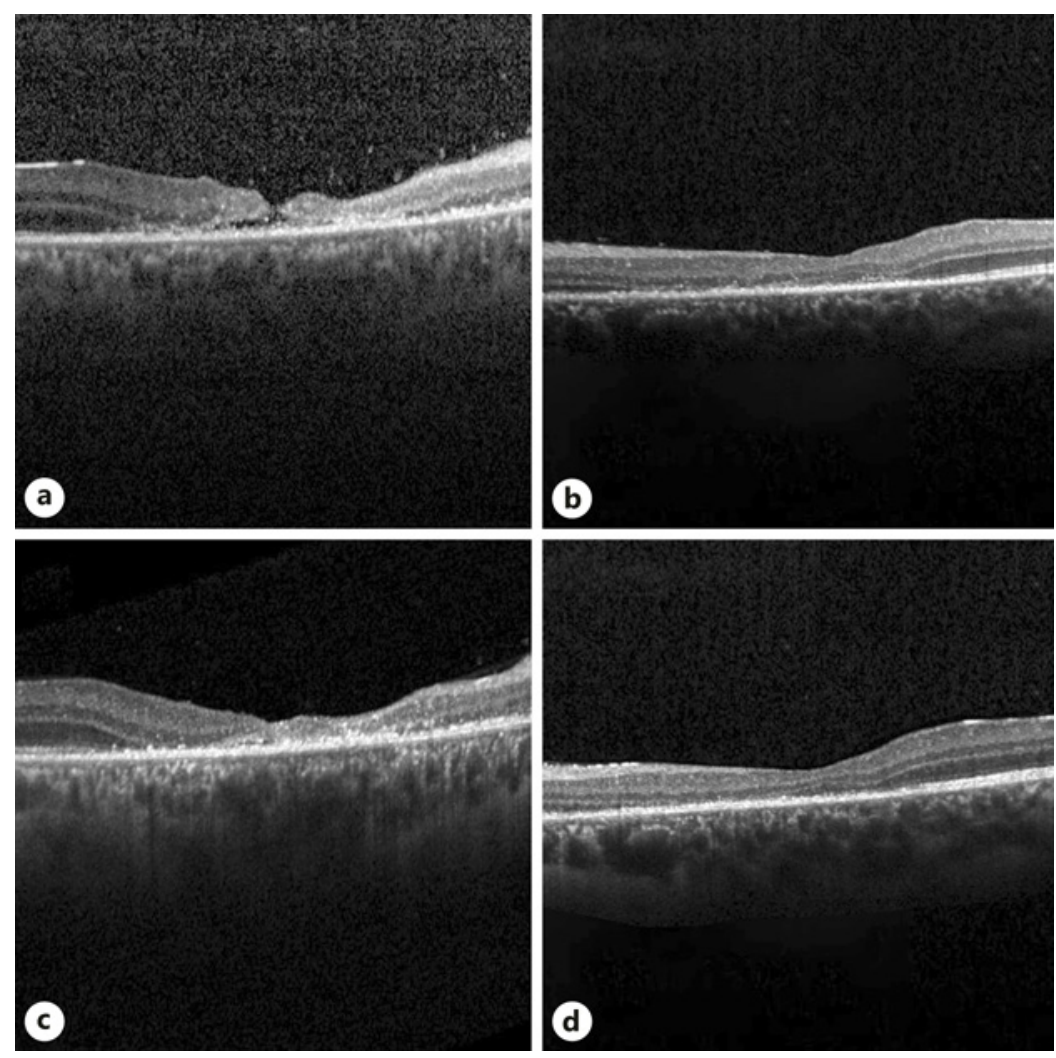

Fig. 3. Spectral domain - optical coherence tomography (Heidelberg Engineering Inc., Heidelberg, Germany) showing a macular hole at initial presentation on RE (a) with spontaneous closure at 6-weeks follow-up (b); disruption of the IS/OS junction with corresponding increased reflectivity at first presentation on left eye (c) and increased external layers atrophy after 6 weeks (d). RE, right eye; IS/OS, inner/outer segment.

\section{Discussion}

While the pandemic does not affect ophthalmologists at first glance, they have a role to play. Maintaining effective emergency care is essential despite the health-care infrastructure should be directed at minimizing transmission risks [8]. Management of acute traumatic maculopathy is no consensual. Some authors describe off-label early intravitreal triamcinolone $(0.05 \mathrm{~mL} / 2 \mathrm{mg})$ use, while central macular thickness is increased [9]. Pars plana vitrectomy is usually performed in patients with persistent vitreous hemorrhage or retinal detachment. Traumatic maculopathy after blunt trauma often causes poor visual outcome despite preservation of the ellipsoidal zone and the interdigital zone is predictable of good visual outcome [10]. In our case, the recovery remained limited despite prompt care. Despite an improvement in vision, we can wonder if introduction of treatments 1 week earlier might have allowed a better recovery. Multifocal electroretinography was not performed but would probably have shown a decrease in amplitude in the central area [11].

This case seems to point a resurgence of domestic accidents during worldwide pandemic with general confinement. Early detection of posterior segment damage after blunt trauma is important even if recovery might be limited by structural damages. 
Bennedjai et al.: Bilateral Traumatic Maculopathy after Closed-Globe Injury

\section{Statement of Ethics}

This research was conducted ethically in accordance with the World Medical Association Declaration of Helsinki. The subject had given his written informed consent for publication of its case.

\section{Conflict of Interest Statement}

All authors certify that they have no affiliations with or involvement in any organization or entity with any financial interest or nonfinancial interest in the subject matter or materials discussed in this manuscript.

\section{Funding Sources}

No funding was received for this research.

\section{Author Contributions}

Dr. Bennedjai wrote the article, Dr. Adam detected the macular atrophy, Dr. Akesbi did the first review of the article, Dr. Rodallec did the follow-up examination, Dr. Vidal did the first consultation, Dr. Gaillard gathered iconography, and Pr. Nordmann did the final review. All the authors approve the final version of the manuscript for publication.

\section{References}

1 Wu P, Duan F, Luo C, Liu Q, Qu X, Liang L, et al. Characteristics of ocular findings of patients with coronavirus disease 2019 (COVID-19) in Hubei Province, China. JAMA Ophthalmol. 2020 May 1;138(5):575-8.

2 World Health Organisation. Statement on the second meeting of the International Health Regulations (2005) Emergency Committee regarding the outbreak of novel Coronavirus (2019-nCoV); 2020.

3 Randelli PS, Compagnoni R. Management of orthopaedic and traumatology patients during the Coronavirus disease (COVID-19) pandemic in northern Italy. Knee Surg Sports Traumatol Arthrosc. 2020 Apr 25;28(6): 1683-9.

4 Ahn SJ, Woo SJ, Kim KE, Jo DH, Ahn J, Park KH. Optical coherence tomography morphologic grading of macular commotio retinae and its association with anatomic and visual outcomes. Am J Ophthalmol. 2013;156(5): 994-e1.

5 Blanch RJ, Good PA, Shah P, Bishop JR, Logan A, Scott RA. Visual Outcomes after blunt ocular trauma. Ophthalmology. 2013;120(8):1588-91.

6 Souza-Santos F, Lavinsky D, Moraes NS, Castro AR, Cardillo JA, Farah ME. Spectral-domain optical coherence tomography in patients with commotio retinae. Retina. 2012;32(4):711-8.

7 American Academy of Ophthalmology. The Eye M.D. Association: Posterior segment manifestations of trauma. In: Basic and clinical science course, section 13: retina and vitreous. Leo; 2011-2012.

8 Lim LW, Yip LW, Tay HW, Ang XL, Lee LK, Chin CF, et al. Sustainable practice of ophthalmology during COVID19: challenges and solutions. Graefes Arch Clin Exp Ophthalmol. 2020 Jul;258(7):1427-36.

9 Mendes S, Campos A, Beselga D, Campos J, Neves A. Traumatic maculopathy 6 months after injury: a clinical case report. Case Rep Ophthalmol. 2014 Mar 1;5(1):78-82.

10 Chen KJ, Sun MH, Sun CC, Wang NK, Hou CH, Wu AL, et al. Traumatic maculopathy with massive subretinal hemorrhage after closed-globe injuries: associated findings, management, and visual outcomes. Ophthalmol Retina. 2019 Jan;3(1):53-60.

11 Saleh M, Letsch J, Bourcier T, Munsch C, Speeg-Schatz C, Gaucher D. Long-term outcomes of acute traumatic maculopathy. Retina. 2011 Nov;31(10):2037-43. 